\title{
ARTIGOS
}

Submetido 04.01.2016. Aprovado 11.08.2016

Avaliado pelo processo de double blind review. Editor Científico: Cesar Alexandre de Souza

DOI: http://dx.doi.org/10.1590/So034-759020170107

\section{MODELO ESTRUTURAL DE GOVERNANÇA DA INFORMAÇÃO PARA BANCOS}

\author{
Information governance structural model for banks \\ Modelo estructural de gobernanza de la información para bancos
}

\section{FERNANDO DE ABREU FARIA \\ fernando.afaria@outlook.com Professor do Centro Universitário Alves Faria, Programa de Mestrado Profissional em Administração - Goiânia-GO, Brasil}

\section{ANTONIO CARLOS GASTAUD MAÇADA \\ acgmacada@ea.ufrgs.br Professor da Universidade Federal do Rio Grande do Sul, Escola de Administração - Porto Alegre - RS, Brasil}

\section{KULDEEP KUMAR}

kuldeep.x.kumar@gmail.com Professor da Florida International University, Department of

Management \& International

Business - Miami - Florida, Estados Unidos da América

\section{RESUMO}

A indústria bancária é reconhecida por ser uma das que mais investem em tecnologia da informação (TI) no Brasil e no mundo, por possuir processos de negócios bem definidos e por ser dinâmica na adoção de novas tecnologias e processos. Nesse contexto, com os dados provenientes de uma pesquisa survey, realizada com os executivos de TI de bancos que atuam no Brasil, foi testado um modelo de regressão estrutural de governança da informação (GI). 0 objetivo do trabalho é validar um modelo de GI para os bancos. Os resultados permitiram concluir que, na percepção dos executivos de TI que participaram da pesquisa, os fatores da GI - políticas, sistemas (SI/TI) e estrutura - têm efeitos diretos e indiretos sobre o valor.

PALAVRAS-CHAVE | Governança da informação, executivos de tecnologia da informação, bancos, modelagem de equações estruturais, modelo de mensuração.

\section{ABSTRACT}

The banking industry is recognized as one of the highest information technology (IT) investments in Brazil and worldwide, by having well-defined business processes, and its dynamism in adopting new technologies and processes. In this context, with data from a survey conducted with IT executives of banks operating in Brazil, a structural regression model of information governance (IG) was tested. The main objective is to validate a GI model for banks. The results showed that, in the perception of the IT executives surveyed, the information governance factors - Policies, Systems (IS / IT) and Structure have direct and indirect effects on value.

KEYWORDS I Information governance, information tecnology executives, banks, structural equation modeling, measurement model.

\section{RESUMEN}

La industria bancaria es reconocida por ser una de las que más invierten en TI en Brasil y en el mundo, por poseer procesos de negocios bien definidos y por ser dinámica en la adopción de nuevas tecnologías y procesos. En ese contexto, con los datos provenientes de una encuesta (survey), realizada con los ejecutivos de TI de bancos que actúan en Brasil, se probó un modelo de regresión estructural de gobernanza de la información (GI). El objetivo del trabajo es validar un modelo de Gl para los bancos. Los resultados permitieron concluir que, para los ejecutivos de TI que participaron en la encuesta, los factores de GI -políticas, sistemas (SI/TI) y estructura- tienen efectos directos e indirectos sobre el valor.

PALABRAS CLAVE / Gobernanza de la información, ejecutivos de Tecnología de la Información, bancos, modelado de ecuaciones estructurales, modelo de medición. 


\section{INTRODUÇÃO}

Neste início de século, as pessoas e as organizações convivem em um ambiente caracterizado pela abundância de dados, criados e multiplicados em velocidade espantosa. Segundo o International Data Corporation (IDC, 2014), o universo digital (definido como uma medida de todo dado digital criado, replicado e consumido no mundo no período de um ano) está dobrando de tamanho a cada dois anos e, em 2020, alcançará 44 zettabytes (ou 44 trilhões de gigabytes).

A expansão do universo digital tem levado as organizações a repensar suas estratégias em relação à guarda e uso da informação. As firmas e indústrias estão se tornando mais digitais, dependentes das novas tecnologias de comunicação e conectividade, em um contexto caracterizado pelo crescimento acentuado no volume e na complexidade dos dados, em que o desafio colocado é não perder sua habilidade de gerar valor a partir deles (Faria \& Sympson, 2013). A abundância de informação nas organizações oferece um grande potencial de riqueza, mas também traz riscos, que precisam ser mitigados. Por isso, algumas delas estão estabelecendo corpos formais de governança para criar estratégias, políticas e procedimentos em torno da distribuição da informação dentro e fora da empresa. Nesse grupo, estão os bancos, reconhecidos pelo seu dinamismo e elevado grau de maturidade nas suas práticas de tecnologia da informação (TI) e de negócios, representantes da indústria que mais investe em TI no mundo (Beccalli, 2007, p. 1) e que passou por grandes transformações nos últimos anos (Soares, 2011, p. 11)

Em uma economia da informação, as empresas devem aproveitar os seus dados para melhorar os processos de negócios, lançar produtos e serviços inovadores e encantar seus clientes (Beath, Becerra-Fernandez, Ross, \& Short, 2012). Em relação a esses últimos, Soares (2011) afirma que a governança da informação (Gl) é crítica para os bancos, uma vez que eles estão cada vez mais centrados nos clientes. A GI pressupõe a existência de políticas e práticas para o gerenciamento, uso, melhoria e proteção da informação que permeiam toda a organização (Soares, 2011). Auxilia diretamente a definição das estratégias do negócio, seja em cenários estáveis ou de mudança contínua, ao oferecer o insumo necessário no processo decisório: informação.

A GI é uma área recente de pesquisa (Grembergen \& Haes, 2009), e, conforme Kooper, Maes e Lindgreen (2011), esse conceito foi introduzido cientificamente em 2004, por Donaldson e Walker, na National Health Society (NHS). 0 estudo quantitativo pretende contribuir para a construção teórica do tema ao apresentar um modelo validado com executivos de TI de bancos e testado estatisticamente com o uso de equações estruturais. Se as relações teóricas propostas na pesquisa com os bancos são estatisticamente significantes, elas podem indicar caminhos às organizações que desejam investir em um programa de GI para adicionar valor pelo uso mais eficiente das suas informações.

Portanto, este trabalho propôs-se a validar, com base na abordagem de Koufteros (1999) e Koufteros, Babbar, e Khaigobadi (2009), um modelo de regressão estrutural de GI para os bancos, que inclui relações diretas e indiretas entre os fatores. Com o modelo, testado com base na percepção dos executivos de TI que participaram da pesquisa, é possível identificar os fatores e itens que podem ser considerados em um programa de GI nos bancos.

\section{REVISÃO DA LITERATURA}

Na revisão da literatura, foram feitas buscas na base de dados da biblioteca virtual da Associação de Sistemas de Informação (AIS), com foco nos journals da Basket of 8 , que significa o grupo dos oito principais periódicos de referência na área de SI apontados pela AIS, quais sejam: European Journal of Information Systems; Information Systems Journal; Information Systems Research; Journal of AIS; Journal of Information Technology; Journal of MIS; Journal of Strategic Information Systems e MIS Quarterly.

Para isso, utilizaram-se as seguintes palavras-chave: information governance, data governance, governança da informação e governança de dados. De acordo com Booth, Papaioannou, e Sutton (2012), as palavras-chave devem ser escolhidas pelo pesquisador de acordo com os objetivos de sua pesquisa, podendo ser adaptadas ou reduzidas ao longo da pesquisa, mas devem ser as mesmas para todas as bases de dados em que a busca foi realizada.

Complementarmente, foram realizadas buscas nas seguintes bases de dados: EBSCOHost, Google Acadêmico e Web of Science, com os mesmas palavras-chave citadas anteriormente. Em todo esse processo de revisão, não foram encontradas publicações que apresentassem um modelo de GI validado estatisticamente.

São apresentados, a seguir, conceitos sobre GI, o modelo de GI e as hipóteses de pesquisa propostas no trabalho.

\section{Governança da Informação}

Grembergen e Haes (2009) indicaram, em seu trabalho, o surgimento de uma nova disciplina na área de governança, a GI. Ela surge para preencher um espaço nas organizações não atendido pela governança da TI, primeiro recolocando a informação como o recurso essencial e, segundo, demonstrando que o uso da informação, e não apenas a sua produção e armazenamento, deve ser considerado nos processos de governança (Kooper et al., 2011). 
Nas definições encontradas na literatura, por meio da repetição de diversos termos, é possível inferir o escopo de ação da GI. Esses termos são regras, normas, políticas, ética, cultura, conteúdo corporativo, direitos decisórios, accountability, compliance, uso apropriado, alcance em toda a empresa, valor, pessoas, processos, ferramentas.

Para explicitar o que é GI, três definições foram selecionadas, por bem caracterizarem seu significado e abrangência. A primeira, de Kooper et al. (2011), “Governança da informação envolve o estabelecimento de um ambiente e de oportunidades, regras e direitos decisórios para a valoração, criação, coleta, análise, distribuição, armazenamento, uso e controle de informações" (p. 195); a segunda, de Faria, Maçada e Kumar (2013), “Governança da informação refere-se ao estabelecimento de políticas, por meio de estruturas formais, que definem regras, procedimentos e direitos decisórios sobre a gestão da informação, de forma a mitigar o risco regulatório e operacional, reduzir custos e otimizar o desempenho da organização" (p. 4444); e a terceira, de Smallwood (2014),
“Governança da informação é um subconjunto da governança corporativa, e inclui os principais conceitos de gerenciamento de registros, gerenciamento de conteúdo, de TI e governança de dados, segurança da informação, privacidade de dados, gestão de riscos, preparação para litígios, conformidade regulatória, preservação digital a longo prazo, e até mesmo inteligência de negócios" (p. 5).

\section{0 modelo e as hipóteses de pesquisa}

A identificação dos fatores da GI e dos seus itens no modelo proposto é baseada em elementos da teoria da agência, da teoria da visão baseada em recursos da firma (RBV) e da teoria das capacidades dinâmicas, com posterior validação pela utilização de técnicas qualitativas, com a participação de 16 altos executivos de TI de bancos no Brasil, em Hong Kong e nos Estados Unidos (Faria et al., 2013).

Algumas publicações indicaram possibilidades de modelos para a GI, conforme listado no Quadro 1.

Quadro 1. Modelos de GI anteriores

\begin{tabular}{|c|c|}
\hline Modelo de GI & Referência \\
\hline $\begin{array}{l}\text { São características de um modelo de GI: definição clara de papéis e responsabilidades; estabelecimento de } \\
\text { um corpo central de governança; suporte top-down; estabelecimento de um programa educativo; introdução } \\
\text { de padrões com flexibilidade. }\end{array}$ & The Economist (2008) \\
\hline $\begin{array}{l}\text { Gl envolve a definição de políticas, procedimentos e controles para gerenciar a informação em conformidade } \\
\text { com as exigências regulatórias externas e internas. }\end{array}$ & Smalwood (2011) \\
\hline Um modelo de GI com três dimensões, valor, qualidade e compliance. & Lajara e Maçada (2013) \\
\hline
\end{tabular}

A partir das diversas alternativas, este trabalho propõe um modelo diferente, composto por três construtos básicos para a GI, políticas, sistemas (SI/TI) e estrutura, todos eles associados à geração de valor pela organização. 0 modelo, que foi testado estatisticamente, baseia-se no fato de que qualquer ação de governança é iniciada pelo estabelecimento de uma política. Esta só é materializada dentro de uma organização nos dias de hoje quando apoiada pela TI, e está sob a responsabilidade de um componente de governança (do inglês governance body) que presta contas e responde por ela.

0 desenvolvimento das hipóteses de pesquisa considerou as possibilidades de relações entre os construtos da GI. A Figura 1 apresenta o modelo de pesquisa utilizado no estudo quantitativo.
Figura 1. Modelo de pesquisa

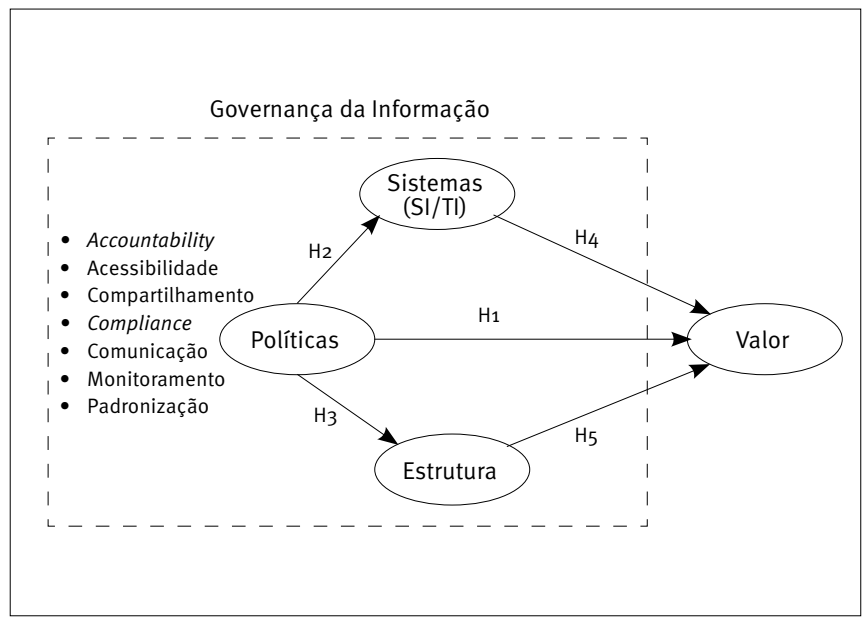


Os construtos, os fatores ou as variáveis presentes no modelo de pesquisa para a GI são: políticas, que representa as políticas e práticas relacionadas à GI na organização, envolve itens relativos a accountability, acessibilidade, compartilhamento, compliance, comunicação, monitoramento e padronização; sistemas (SI/TI), que representa o conjunto de sistemas e tecnologias da informação disponíveis na organização, que dão suporte à GI; estrutura, que representa a estrutura formal de governança, define e habilita as políticas e práticas de GI na organização; valor, que representa o valor percebido o qual é gerado pela organização como resultado das políticas e práticas de GI.
No modelo de pesquisa, as variáveis sistemas (SI/TI) e estrutura ligam causa (as políticas de GI) e efeito (o valor), são mediadoras. Essas variáveis seguem a variável independente (as políticas de GI) e precedem a variável dependente (o valor). Além disso, supõe-se a existência de correlação entre as variáveis sistemas ( $\mathrm{SI} / \mathrm{TI})$ e estrutura (as mediadoras) e a variável independente (políticas).

As hipóteses de pesquisa exploram principalmente as relações entre os fatores da GI e o valor. O Quadro 2 relaciona as cinco hipóteses propostas no trabalho, indicando também os elementos teóricos e as referências utilizados em sua construção.

\section{Quadro 2. As hipóteses de pesquisa}

\begin{tabular}{|c|c|c|c|}
\hline $\mathrm{H}_{4}$ & $\begin{array}{l}\text { O fator Sistemas (SI/TI) está } \\
\text { positivamente associado ao Valor. }\end{array}$ & $\begin{array}{l}\text { A indústria bancária é caracterizada por ser altamente } \\
\text { competitiva e dinâmica. Mais que isso, nessa indústria, a } \\
\text { relação entre a TI e o negócio bancário é muito estreita. } \\
\text { A TI (ou os investimentos em TI) está relacionada com } \\
\text { os resultados, o desempenho ou o valor gerado nas } \\
\text { organizações. } \\
\text { As firmas investem em TI no pressuposto que essas } \\
\text { tecnologias irão influenciar o desempenho. Na era pós- } \\
\text { paradoxo da produtividade, os pesquisadores se voltam } \\
\text { para descobrir como, ao invés de, se a TI contribui para o } \\
\text { desempenho da empresa. }\end{array}$ & $\begin{array}{l}\text { Nakata, Zhu, e Kraimer, 2008; } \\
\text { Faria e Maçada, 2011; Qrunfleh e } \\
\text { Tarafdar, } 2012 . \\
\text { Tallon, 2007; Campo, Rubio, e } \\
\text { Yague, 2010. }\end{array}$ \\
\hline
\end{tabular}

As cinco hipóteses previstas no modelo buscam verificar as relações entre os construtos políticas e valor, políticas e sistemas (SI/TI), sistemas (SI/TI) e valor, políticas e estrutura, e estrutura e valor. 


\section{METODOLOGIA}

O estudo sobre o tema GI na indústria bancária foi realizado em três etapas. A primeira, uma revisão da literatura que identificou fatores e itens para um modelo de GI; a segunda, um estudo qualitativo com o objetivo de validar, junto a um grupo de altos executivos de TI dos bancos, os itens e fatores que poderiam compor um modelo de Gl; e a terceira, um estudo quantitativo com a proposição de um modelo de regressão estrutural. 0 presente artigo apresenta uma parte desse estudo, que foi realizada durante a etapa quantitativa, aquela em que foi validado o modelo estrutural.

Conforme Weston e Gore (2006), a modelagem de equações estruturais (do inglês structural equation modeling
- SEM) é uma combinação de análise fatorial e análise de caminhos, o que leva o pesquisador a pensar sobre os seus dois componentes primários, o modelo de mensuração e o modelo estrutural. 0 primeiro descreve os relacionamentos entre as variáveis observadas (os indicadores) e os seus construtos, enquanto o segundo descreve os relacionamentos entre os construtos. Quando o modelo de mensuração e o modelo estrutural são considerados em conjunto, o modelo pode ser chamado de modelo estrutural completo. Para validação do modelo estrutural, foi utilizado o paradigma proposto nos trabalhos de Koufteros (1999) e Koufteros et al. (2009), que é apresentado no Quadro 3.

\section{Quadro 3. Paradigma para validação de modelos estruturais}

\begin{tabular}{|c|c|}
\hline Etapa & Atividade \\
\hline Pré-teste & $\begin{array}{l}\text { Análise de outliers; } \\
\text { Índice de correlação de item total corrigido (CITC); } \\
\text { Alfa de Cronbach (instrumento preliminar e final); } \\
\text { Análise fatorial exploratória convergente; } \\
\text { Eliminação de itens. }\end{array}$ \\
\hline $\begin{array}{l}\text { Estudo completo - } \\
\text { Purificação da base e } \\
\text { confiabilidade }\end{array}$ & $\begin{array}{l}\text { Purificação da base de dados com análise de dados omissos, outliers, respondentes não engajados, análise } \\
\text { da multicolinearidade, normalidade, linearidade, homocedasticidade; } \\
\text { Teste de adequação da amostra (KMO e esfericidade de Barlett); } \\
\text { Análise da confiabilidade com Alfa de Cronbach e CITC. }\end{array}$ \\
\hline \multirow[b]{2}{*}{$\begin{array}{l}\text { Análise fatorial } \\
\text { confirmatória }\end{array}$} & $\begin{array}{l}\text { Validação do modelo de mensuração; } \\
\text { Validação do modelo de mensuração inicial (valores t, cargas fatoriais, índices de ajustamento); } \\
\text { Uso dos valores de covariância residual padronizada e dos índices de modificação; } \\
\text { Validação do modelo de mensuração final (valores t, cargas fatoriais, índices de ajustamento, validade } \\
\text { discriminante (AVE), confiabilidade composta). }\end{array}$ \\
\hline & $\begin{array}{l}\text { Testes com modelos alternativos; } \\
\text { Identificação da relação teórica entre os construtos e os itens; } \\
\text { Validação dos fatores; } \\
\text { AFC para o modelo de primeira ordem com um único fator latente; } \\
\text { AFC para o modelo de primeira ordem com os fatores ortogonais (não correlacionados); } \\
\text { AFC para o modelo de primeira ordem com todos os construtos correlacionados; } \\
\text { AFC para o modelo de segunda ordem; } \\
\text { Comparação entre os modelos. }\end{array}$ \\
\hline
\end{tabular}

Primeiramente, foi feita uma pesquisa survey como um pré-teste e, em seguida, após ajustes no instrumento, foi realizada a survey final. Ambas foram realizadas exclusivamente com executivos de TI de bancos que operam no Brasil. Essas surveys tiveram como objetivo validar os fatores e itens do modelo de GI para os bancos. Depois de coletados os dados, eles foram submetidos às análises estatísticas e, posteriormente, foi utilizada a técnica de modelagem de regressão estrutural para validar o modelo de GI proposto. 


\section{População e amostra}

A população-alvo da pesquisa é formada por todos os executivos de TI dos bancos brasileiros. Para buscar a participação dos executivos, a exigência foi que o executivo de TI respondente ocupasse um cargo de chefia em sua organização. As amostras do estudo (pré-teste e estudo completo) são não probabilísticas por conveniência. Nesta pesquisa, no estudo completo, foi utilizada a amostragem "bola de neve" (do inglês snowball sampling). Os dados foram coletados diretamente dos questionários aplicados sobre os executivos de TI de diversos bancos brasileiros, públicos e privados.

Para alcançar o público-alvo, o pesquisador (um ex-CIO de banco) elaborou uma lista dos bancos no Brasil em que possuía contatos com o $\mathrm{ClO}$ ou com outro executivo de alto nível. Posteriormente, foi feito o contato com o $\mathrm{CIO}$ ou com um alto executivo de cada um dos bancos relacionados por meio presencial, telefônico ou e-mail, ocasião em que foi apresentada a pesquisa e solicitada a participação de outros executivos de TI do mesmo banco ou de seus colegas de outros bancos. Tal procedimento foi repetido em todos os bancos cujos executivos participaram da pesquisa. A lista foi ampliada com a inclusão de executivos de alto nível de outros bancos, que foram indicados pelos contatos da lista inicial. Embora seja não probabilística, a amostra obtida é variada e significativa, pois contém um número expressivo de executivos de TI dos maiores bancos do País, além de incluir bancos de diferentes portes e características.

0 pré-teste foi realizado em maio de 2013 , teve uma amostra por conveniência de 35 executivos de TI dos bancos, e suas respostas foram coletadas por intermédio de aplicativo específico para tratamento de questionários na internet. Para a survey final, realizada entre junho e agosto de 2013, o instrumento foi aplicado sobre uma amostra da população-alvo composta por 222 executivos de TI dos bancos. No processo de purificação dos dados, um questionário foi rejeitado por ter sido considerado de respondente não engajado. Participaram do estudo completo (a survey final) executivos de TI de 40 bancos no Brasil. Se se considerar o ranking disponibilizado pelo Banco Central do Brasil (2013), intitulado "50 maiores bancos e o consolidado do sistema financeiro nacional”, para a posição de junho de 2013, pode-se afirmar que a quase totalidade dos bancos participantes na referida amostra está inserida no grupo dos 50 maiores bancos (classificação por ativo total) do País.

Entre os 221 respondentes que compuseram a amostra do estudo completo, $14,8 \%$ eram membros do board, executivos do nível estratégico, diretores de TI ou chefes de unidade de TI; 47,9\% dos executivos tinham mais de 20 anos de trabalho na área de $\mathrm{Tl}$; e $52,4 \%$ dos respondentes trabalhavam havia mais de 20 anos nos seus respectivos bancos. Entre os respondentes, estavam 182 executivos de bancos múltiplos, 22 de bancos comerciais, $7 \mathrm{de}$ bancos de investimento, 2 de bancos de desenvolvimento e 8 que não informaram qual o registro do seu banco no Banco Central.

\section{Desenvolvimento do instrumento de coleta de dados}

Para a realização da survey com os executivos de TI dos bancos, o pesquisador optou pelo uso de questões de concordância, de modo a capturar a percepção dos executivos sobre os diversos itens, com a adoção de uma escala Likert de 7 pontos.

Os construtos são medidos, neste trabalho, com base na percepção dos executivos de TI. Medir resultados com base na percepção de executivos não é novidade nos estudos organizacionais. Campo, Rubio, e Yagüe (2010) afirmam que a variável de percepção é uma variável proxy para os resultados reais, que normalmente são difíceis de obter. De acordo com Dess e Robinson (1984), as medidas de percepção de desempenho são comparáveis às medidas objetivas. Nas palavras de Tallon, Kraemer, e Gurbaxani (2000), “as medidas de percepção e as medidas objetivas podem coexistir" (p. 149).

0 instrumento foi submetido a um processo para validação de face e de conteúdo com acadêmicos e executivos brasileiros com experiência na área de TI. Primeiro, ele foi avaliado por três doutorandos da área de SI/TI, todos em fase de tese, para uma validação de face e de conteúdo. Depois, foi submetido ao crivo de dois executivos da área de TI nos bancos. O documento foi atualizado, incorporando algumas sugestões de melhoria relativas aos termos utilizados e à clareza de algumas questões.

Complementarmente, foi aplicada a técnica do card sorting com a participação de três executivos de TI de bancos, para validar os construtos e itens do instrumento. 0 instrumento utilizado no pré-teste era composto por duas seções de perguntas. A primeira seção continha as questões relativas aos fatores da Gl e ao valor percebido como resultado da GI. A segunda apresentava questões relativas ao perfil dos respondentes.

Por fim, deve-se registrar que o questionário foi construído e distribuído com o auxílio de software operado na internet. Adicionalmente, foi oferecida aos respondentes a opção do questionário impresso. Pela internet, foram obtidas 146 respostas, enquanto a opção impressa foi utilizada por 76 executivos.

\section{Tratamento estatístico dos dados}

O trabalho utilizou a modelagem de equações estruturais (SEM), mais precisamente a análise fatorial confirmatória (AFC) e a modelagem de regressão estrutural. 
Para realizar as análises estatísticas mais triviais, como as estatísticas descritivas, a análise fatorial, confiabilidade, entre outras, foi utilizado o software SPSS versão 21. Para o desenvolvimento da análise fatorial confirmatória e a modelagem de regressão estrutural, foi utilizado o software AMOS versão 21.

\section{RESULTADOS E DISCUSSÃO}

Os construtos e os seus respectivos itens constantes do instrumento de pesquisa que foi aplicado no estudo completo estão apresentados, em conjunto com algumas estatísticas básicas, na Tabela 1. Parte desses itens foi excluída durante a validação do modelo de mensuração.

\section{Tabela 1. Relação de Construtos e Itens do Instrumento Final}

\begin{tabular}{|c|c|c|c|c|c|c|}
\hline \multicolumn{2}{|c|}{ Construto/Item } & Survey item & CITC & Média & DP & Alfa \\
\hline \multicolumn{2}{|c|}{ Políticas } & & & & & 0,92 \\
\hline PL1 & (AT) & $\begin{array}{l}\text { A liderança executiva estabelece regras de responsabilização sobre o uso } \\
\text { da informação. }\end{array}$ & 0,75 & 5,55 & 1,38 & \\
\hline $\mathrm{PL} 3$ & (AS) & O acesso à informação é controlado por regras corporativas. & 0,60 & 5,80 & 1,32 & \\
\hline PL4 & (AS) & $\begin{array}{l}\text { O funcionário tem acesso apenas às informações corporativas necessárias } \\
\text { ao seu trabalho. }\end{array}$ & 0,63 & 5,23 & 1,51 & \\
\hline PL6 & (CT) & $\begin{array}{l}\text { Temos regras para o compartilhamento de informações entre as unidades } \\
\text { de negócios. }\end{array}$ & 0,70 & 5,15 & 1,41 & \\
\hline $\mathrm{PL} 7$ & $(\mathrm{CL})$ & As informações corporativas obedecem a requisitos de compliance. & 0,58 & 5,73 & 1,08 & \\
\hline PL8 & $(\mathrm{CL})$ & A privacidade das informações é garantida pelas regras de compliance. & 0,60 & 5,64 & 1,29 & \\
\hline PL9 & $(\mathrm{CM})$ & $\begin{array}{l}\text { Temos um processo de comunicação interno sobre as práticas relativas ao } \\
\text { uso da informação. }\end{array}$ & 0,63 & 5,43 & 1,41 & \\
\hline PL12 & $(\mathrm{MN})$ & Utilizamos métricas para avaliar os resultados das políticas de informação. & 0,68 & 4,14 & 1,61 & \\
\hline PL13 & (PD) & O uso de padrões facilita a nossa gestão da informação. & 0,49 & 5,87 & 1,22 & \\
\hline PL14 & $(\mathrm{PD})$ & Temos regras para padronização da informação. & 0,63 & 5,60 & 1,25 & \\
\hline Siste & $\mathrm{I} / \mathrm{TI})$ & & & & & 0,76 \\
\hline $\mathrm{Sl} 1$ & & $\begin{array}{l}\text { Os sistemas estão preparados para adaptarem-se rapidamente às } \\
\text { mudanças do negócio. }\end{array}$ & 0,64 & 3,84 & 1,68 & \\
\hline $\mathrm{SI} 2$ & & $\begin{array}{l}\text { Os sistemas são efetivos na disponibilização das informações para os } \\
\text { usuários. }\end{array}$ & 0,55 & 5,04 & 1,44 & \\
\hline $\mathrm{SI} 3$ & & $\begin{array}{l}\text { Os sistemas disponibilizam informações para a tomada de decisão em } \\
\text { dispositivos móveis. }\end{array}$ & 0,52 & 4,24 & 1,78 & \\
\hline $\mathrm{SI} 4$ & & $\begin{array}{l}\text { Os sistemas permitem recuperar todas as informações de um cliente por } \\
\text { meio de uma interface única. }\end{array}$ & 0,55 & 3,26 & 1,74 & \\
\hline Valor & & & & & & 0,82 \\
\hline VL1 & & Melhor direcionamento dos investimentos em TI. & 0,67 & 4,98 & 1,55 & \\
\hline VL2 & & Redução do risco regulatório. & 0,51 & 5,70 & 1,25 & \\
\hline $\mathrm{VL} 3$ & & Melhor desempenho operacional. & 0,72 & 5,40 & 1,31 & \\
\hline VL4 & & Diminuição do custo de armazenamento (storage). & 0,55 & 4,56 & 1,63 & \\
\hline $\mathrm{VL} 5$ & & Aprimoramento do processo decisório. & 0,66 & 5,36 & 1,45 & \\
\hline
\end{tabular}

Obs.: AT (accountability); AS (acessibilidade); CT (compartilhamento); CL (compliance); CM (comunicação); MN (monitoramento);

PD (padronização); CITC (correlação item total corrigido); DP (desvio-padrão); a (alfa de Cronbach). 
São 14 itens relativos ao construto políticas, quatro para o construto sistemas (SI/TI), quatro para o construto estrutura e cinco para o construto valor.

Nesta seção, são apresentados a seguir o processo de validação do modelo de mensuração, os testes com modelos alternativos e, por fim, o modelo estrutural proposto com os resultados das hipóteses.

\section{Validação do modelo de mensuração}

A validação do modelo de mensuração foi feita por meio de uma análise fatorial confirmatória (AFC), conforme proposto no paradigma de Koufteros (1999, p. 475). Nele, as etapas um e dois referem-se ao desenvolvimento do instrumento e à coleta de dados. Para iniciar a etapa três da proposta de Kouferos, incluiu-se o modelo de mensuração com seus construtos e itens em um software de modelagem de equações estruturais (AMOS). 0 modelo de mensuração inicial apresentado na Figura 2 possui quatro construtos e 27 itens. As informações que compõem a base de dados já passaram pelo processo de purificação e pelos testes de adequação da amostra final.

Figura 2. Modelo de mensuração inicial

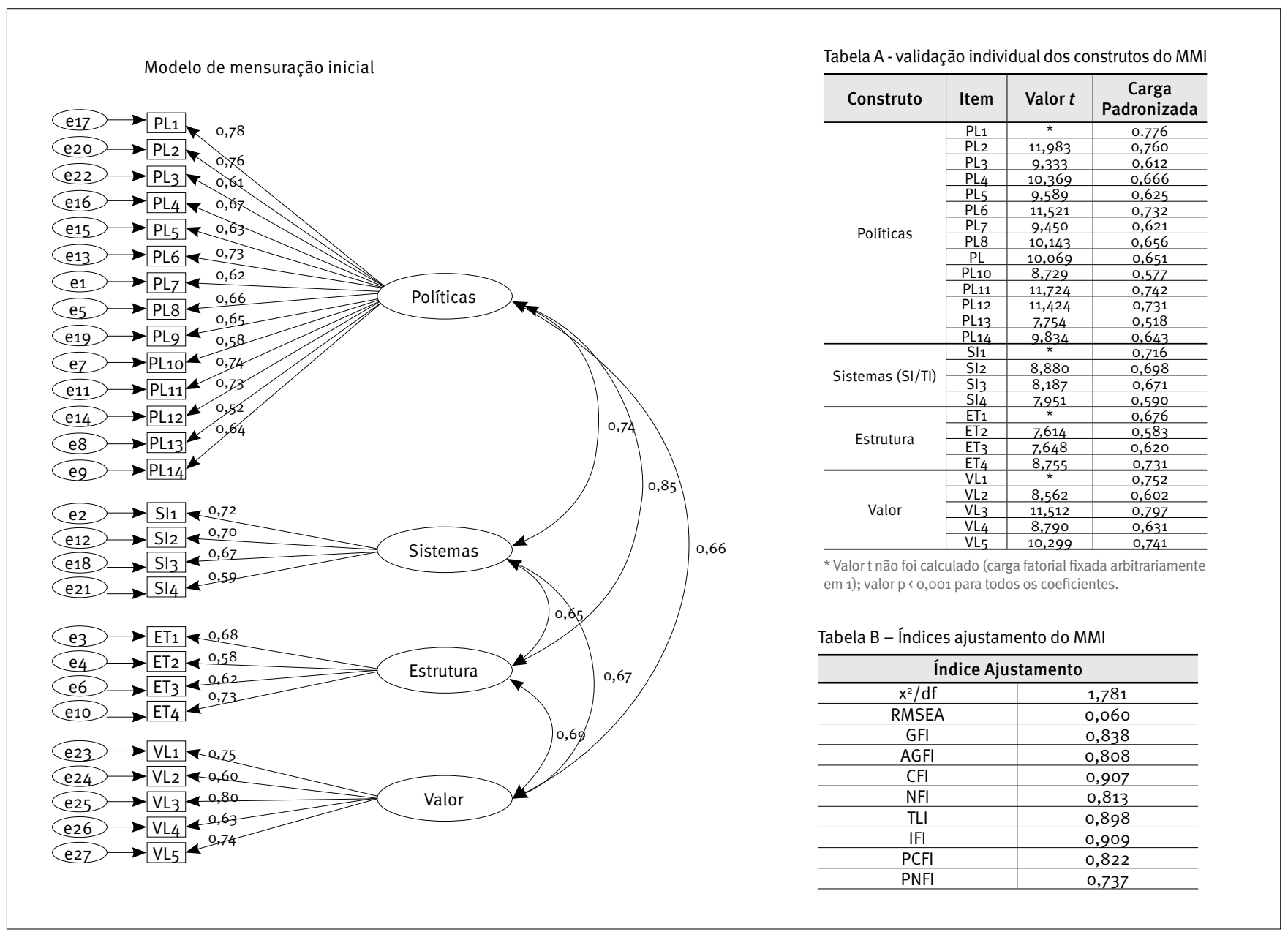

Fonte: AMOS

A etapa três trata da validade convergente, que consiste na observação dos valores t e das cargas fatoriais padronizadas. Segundo Koufteros (1999), não há um valor de corte comumentemente aceito para as cargas dos fatores, mas a validade convergente pode ser avaliada pelo exame da razão das cargas dos fatores e seus respectivos erros-padrão. Em geral, se os valores $t$ são maiores que $|2|$ ou $|2,576|$ então eles são considerados significantes ao nível de 0,05 e 0,01, respectivamente. Na Tabela A da Figura 2, 
estão listados os coeficientes padronizados e os valores $t$ de cada uma das variáveis (ou itens) por construto do modelo. Pode-se observar na tabela que os valores $t$ são superiores a $|2,576| \mathrm{e}$ as cargas fatoriais são superiores a 0,5 para todos os itens dos construtos.

$\mathrm{Na}$ etapa quatro de Koufteros, deve-se avaliar os índices de ajustamento e unidimensionalidade. Para isso, foram analisados os índices de ajustamento, os valores das covariâncias residuais padronizadas (do inglês standardized residual covariances) e os índices de modificação (do inglês modification indices) calculados pelo AMOS para o modelo. Os índices de ajustamento do modelo de mensuração inicial estão listados na Tabela B da Figura 2. Na tabela, pode-se observar que os valores calculados para o modelo estão adequados aos valores recomendados na maioria dos índices. Somente o GFI está um pouco abaixo do valor recomendado.

Na sequência da análise, observou-se, no AMOS, a matriz com os valores de covariância residual padronizada e também os índices de modificação. A respeito desses dois números, Koufteros (1999) afirma que os valores de covariância residual padronizada são altos quando maiores que $|2,58|$ e que os índices de modificação superiores a 15 devem ser observados com atenção. Além disso, Brown e Moore (2012) relatam que os índices de modificação e os resíduos padronizados são, muitas vezes, úteis para determinar as fontes particulares de tensão na solução quando o modelo contém erros menores de especificação. De acordo com esses autores, a razão mais comum para reespecificação do modelo de mensuração é melhorar o seu ajustamento em decorrência de, pelo menos, um dos três seguintes critérios: índices de ajustamento inadequados, resíduos padronizados muito grandes ou índices de modificação que indicam áreas localizadas de ajustamento ruim.

Assim, no processo de avaliação dos valores de covariância residual padronizada, dos índices de modificação e das cargas fatoriais entre os construtos no modelo de mensuração inicial, foram identificadas sete variáveis observadas (itens) que apresentaram problemas em relação aos valores de referência e, por isso, foram retiradas do modelo. Em síntese, foram excluídos do modelo cinco itens do construto políticas, um item do construto estrutura e um item do construto valor. Também foi identificada uma correlação entre dois itens do construto políticas (PL13 e PL14), algo plausível e até certo ponto esperado, já que ambos avaliam a questão das políticas de padronização das informações nos bancos.

No construto políticas, o item PL12 (Utilizamos métricas para avaliar os resultados das políticas de informação) foi retirado por apresentar índices de modificação iguais a 14,021 com o item $\mathrm{PL3}$ (O acesso à informação é controlado por regras corporativas) e 9,930 com o item PL11 (Temos ferramentas que permitem monitorar o uso da informação). Os respondentes não consideraram o item PL12 um elemento das políticas de GI. Não há prejuízo para a questão do monitoramento das informações, uma vez que seu escopo também é medido pelo item PL11 (Temos ferramentas que permitem monitorar o uso da informação). 0 item PL8 (A privacidade das informações é garantida pelas regras de compliance) apresentou covariância residual padronizada de 2,200 com o item ET1 (A governança da informação está ligada à governança corporativa). Da mesma forma que no anterior, entendeu-se que sua exclusão não prejudicaria a avaliação da questão do compliance na pesquisa, considerando-se que o item PL7 (As informações corporativas obedecem a requisitos de compliance) também a considera. O item PL4 (O funcionário tem acesso apenas às informações corporativas necessárias ao seu trabalho) apresentou covariância residual padronizada de 2,273 com o item SI2 (Os sistemas são efetivos na disponibilização das informações para os usuários). Nesse caso, o item PL4 é viabilizado nos bancos pelo uso dos sistemas e dos seus controles. Além disso, a questão da acessibilidade, aqui entendida como o acesso à informação, está também medida pelo item $\mathrm{PL}_{3}(\mathrm{O}$ acesso à informação é controlado por regras corporativas).

Após a exclusão desses três itens, o construto políticas continuou apresentando uma alta correlação com o fator estrutura $(0,83)$. Essa alta correlação certamente traria problemas futuros na análise da validade discriminante dos construtos. Mas, como não há dúvida de que essas duas variáveis latentes claramente representam, do ponto de vista teórico, dois construtos distintos, optou-se por uma solução não tão radical, que consistiria na exclusão do fator. Conforme Brown e Moore (2012, p. 377), a solução para esse problema é juntar os fatores ou eliminar o fator redundante. Assim, foram excluídos os itens PL6 (Temos regras para o compartilhamento de informações entre as unidades de negócios) e PL1o (Comunicamos aos nossos funcionários quando fazem uso impróprio da informação) do construto políticas. Esses dois itens, na visão dos respondentes, estavam muito ligados ao construto estrutura. Após sua exclusão, a correlação entre os fatores caiu para 0,75 , número que, embora ainda seja um pouco alto, ficou mais longe de 1,00 (Brown \& Moore, 2012, p. 373). Em relação a essa correlação entre os fatores, Bagozzi e Yi (2012, p. 15) citam um intervalo entre 0,48 e 0,72.

No construto estrutura, o item ET4 (A governança da informação é aprovada no nível estratégico pelo board) apresentou índices de modificação com outros dois itens dentro do mesmo construto. Com o item ET2 (As áreas de negócios participam das decisões sobre a governança da informação), o índice de modificação foi de 4,126, e, com o item ET3 (Existe uma estrutura formal de governança que define as políticas 
relacionadas à informação), o índice de modificação foi de 5,225. Com esses valores, considerados relativamente baixos, o item poderia ser mantido, mas optou-se pela sua exclusão, pois, além de melhorar significativamente os índices de ajustamento do modelo, ela reduziu a correlação entre os construtos estrutura e valor para o,73.

Após a conclusão da etapa quatro da proposta de Koufteros, que se refere a avaliação dos índices de ajustamento e unimensionalidade, chegou-se ao modelo de mensuração revisado, que é apresentado na Figura 3.

Figura 3. Modelo de mensuração revisado

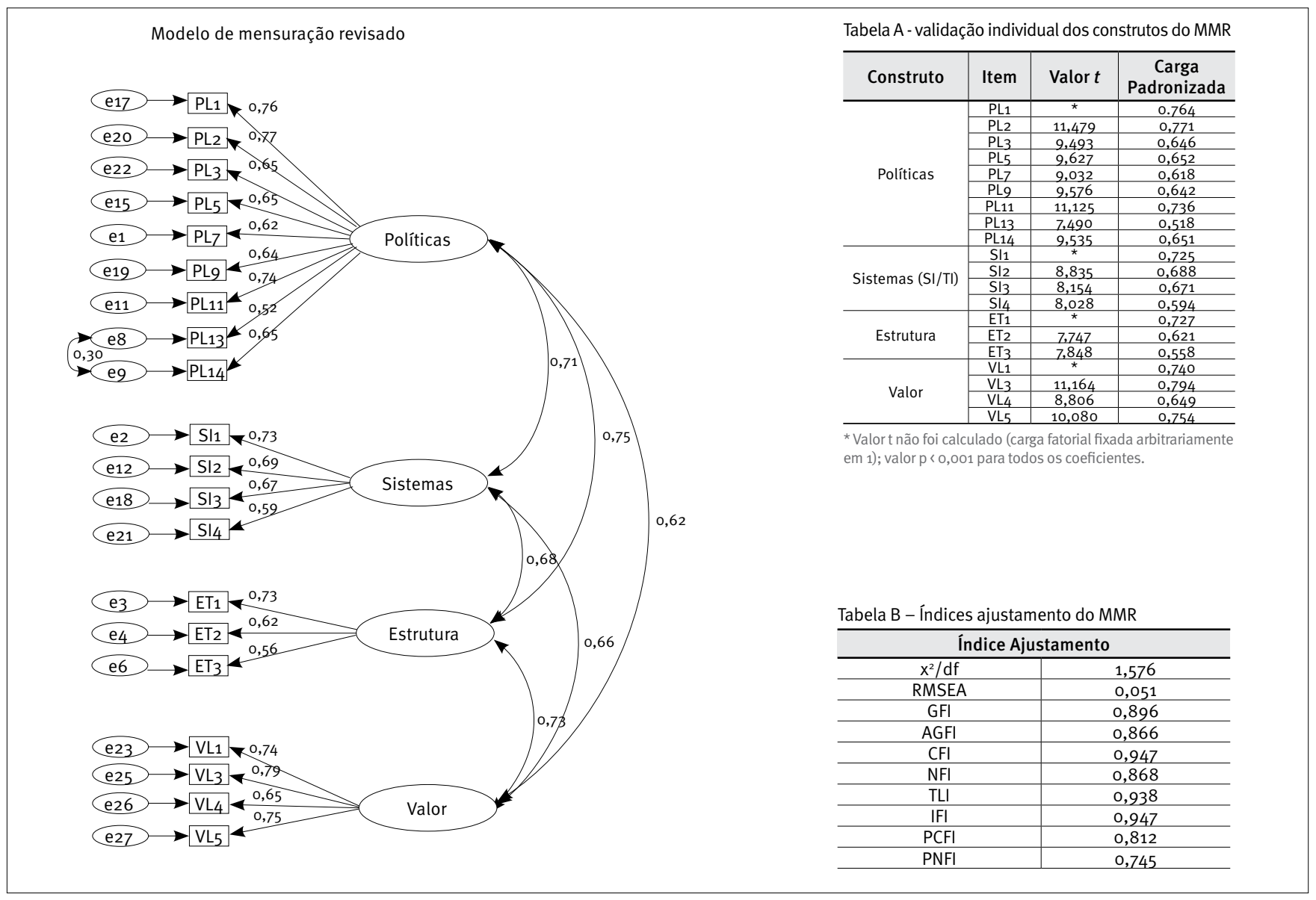

Fonte: AMOS

Conforme pode ser observado por meio de simples comparação com o modelo de mensuração inicial apresentado na Figura 2, o modelo inicial foi reduzido em sete itens e passou a ser composto por 20 itens e quatro construtos no modelo revisado. Essa redução levou a um modelo de mensuração revisado nitidamente melhor que o modelo de mensuração inicial. No modelo revisado, o construto políticas é medido por nove itens, os construto sistemas e valor, por quatro itens cada um, e o construto estrutura, por três.

O modelo de mensuração revisado apresentou correlações entre os construtos e cargas fatoriais entre os itens e os construtos razoáveis. Essas últimas variaram de 0,52 (item PL13 do construto políticas) a 0,79 (item VL3 do construto valor). Dos 20 itens, apenas três apresentaram carga fatorial inferior a o,60, ficando desses três apenas um mais próximo da margem mínima de 0,50.
Para a análise da validade discriminante e da confiabilidade dos construtos, etapas cinco e seis na abordagem de Koufteros, foram calculados a variância média extraída (do inglês Average Variance Extracted, AVE) e o quadrado da correlação entre os fatores. De acordo com Fornell e Larcker (1981), a validade discriminante pode ser verificada pela comparação entre a variância extraída de um fator e as variâncias compartilhadas entre os demais (indicada como sendo o quadrado do coeficiente de correlação entre o construto dado e todos os demais). Os construtos políticas, sistemas (SI/TI), estrutura e valor apresentaram AVE igual a 0,574, 0,577, 0,528 e 0,671 , respectivamente. Todos esses valores foram superiores ao mínimo de 0,5 e também superiores ao quadrado das correlações, o que comprovou a validade discriminante dos construtos do 
modelo de mensuração revisado. A confiabilidade composta foi superior a 0,7 em todos os construtos, foi de 0,923 para o construto políticas, de o,844 para sistemas ( $\mathrm{SI} / \mathrm{TI})$, de 0,769 para estrutura e de 0,890 para valor. Conforme Koufteros (1999), a confiabilidade composta significa que os indicadores de um construto latente são consistentes em sua medição.

Para complementar a avaliação da confiabilidade do modelo de mensuração revisado, a Tabela A da Figura 3 apresenta, para cada fator (construto), os valores $t$ obtidos para os itens do modelo. Todos os valores $t$ são superiores a $|2,576|$, e as cargas dos fatores são superiores a 0,5 para todos os itens. Os números apresentados indicam a confiabilidade do modelo de mensuração revisado.

Com o modelo de mensuração revisado, foram calculados os novos índices de ajustamento, que estão listados na Tabela $B$ da Figura 3. Comparando-se os números das Tabelas B das Figuras 2 e 3, percebe-se a melhora em quase todos os índices de ajustamento. É o caso, por exemplo, do RMSEA, do GFI e do CFI. $\mathrm{O}$ único índice que apresentou uma pequena redução foi o PCFI.

Antes de detalhar a etapa sete, a última da abordagem de Koufteros (1999), referente ao teste do modelo estrutural, procedeu-se a alguns testes com modelos de mensuração alternativos, que são detalhados a seguir. Isso foi feito porque, conforme pode ser observado no modelo de mensuração revisado apresentado na Figura 3, existe uma forte correlação entre os construtos políticas e sistemas (SI/TI) $(0,71)$, entre os construtos políticas e estrutura $(0,75)$, e entre os construtos sistemas $(\mathrm{SI} / \mathrm{TI})$ e estrutura $(0,68)$. E, como foi indicado no modelo de pesquisa deste trabalho (vide Figura 1), esses três construtos (fatores) parecem representar um fator de segunda ordem, a GI.

\section{Modelos de mensuração alternativos}

Um paradigma para avaliar modelos de mensuração de segunda ordem foi apresentado por Koufteros et al. (2009). A abordagem proposta por esses autores é hierárquica e composta dos seguintes passos: (1) Identificação da relação teórica entre os construtos e os itens; (2) Validação dos fatores; (3) AFC para o modelo de primeira ordem com um único fator latente; (4) AFC para o modelo de primeira ordem com os fatores ortogonais (não correlacionados); (5) AFC para o modelo de primeira ordem com todos os construtos correlacionados; (6) AFC para o modelo de segunda ordem; (7) Comparação entre os modelos.

Os passos 1 e 2 foram realizados nas etapas anteriores da pesquisa, e o modelo previsto no passo 5 é o modelo de mensuração revisado. As Figuras $4 \mathrm{a}$ e $4 \mathrm{~b}$ apresentam os modelos alternativos testados.

Figura 4a. Modelos de mensuração alternativos 1 e 2

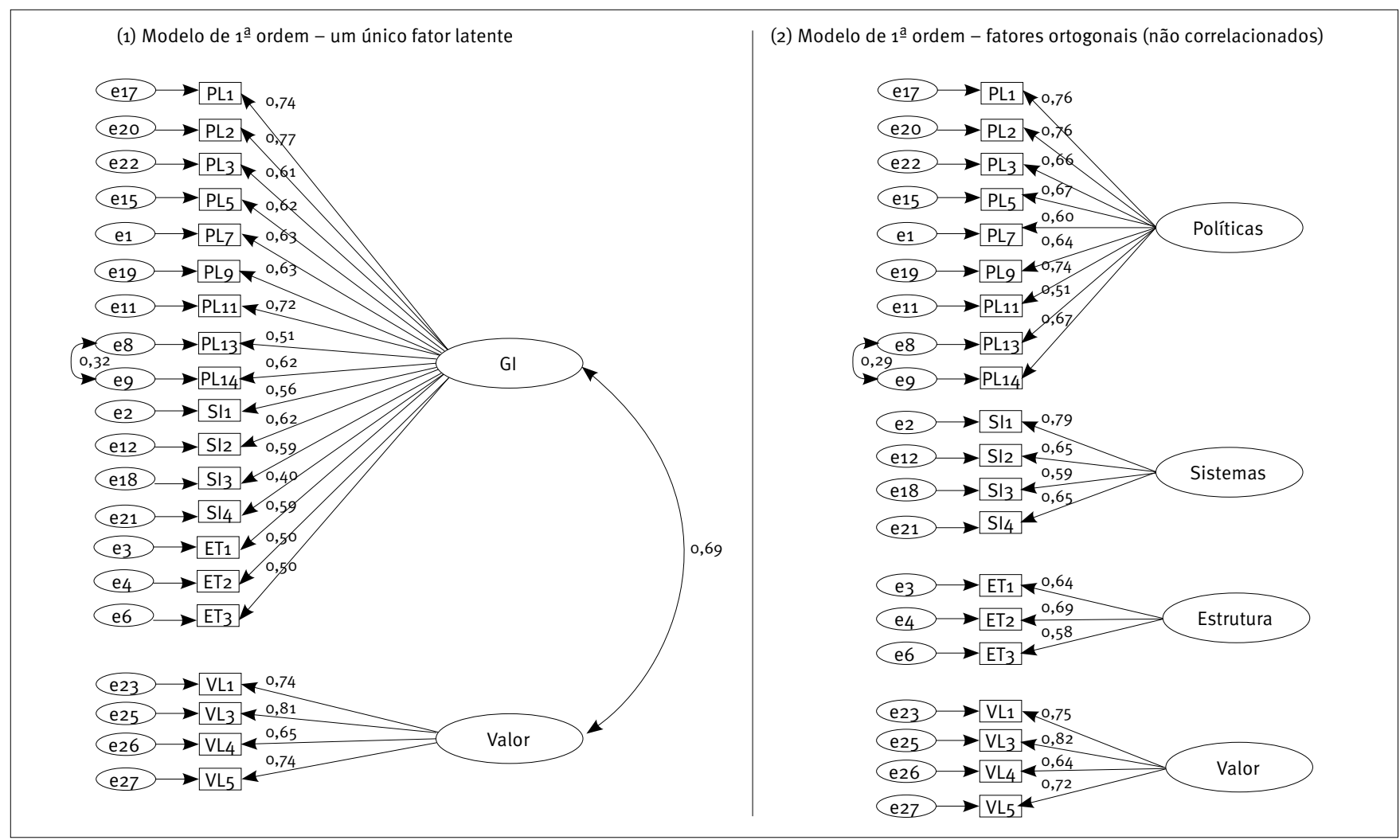

Fonte: AMOS 
Figura 4b. Modelos de mensuração alternativos 3 e 4

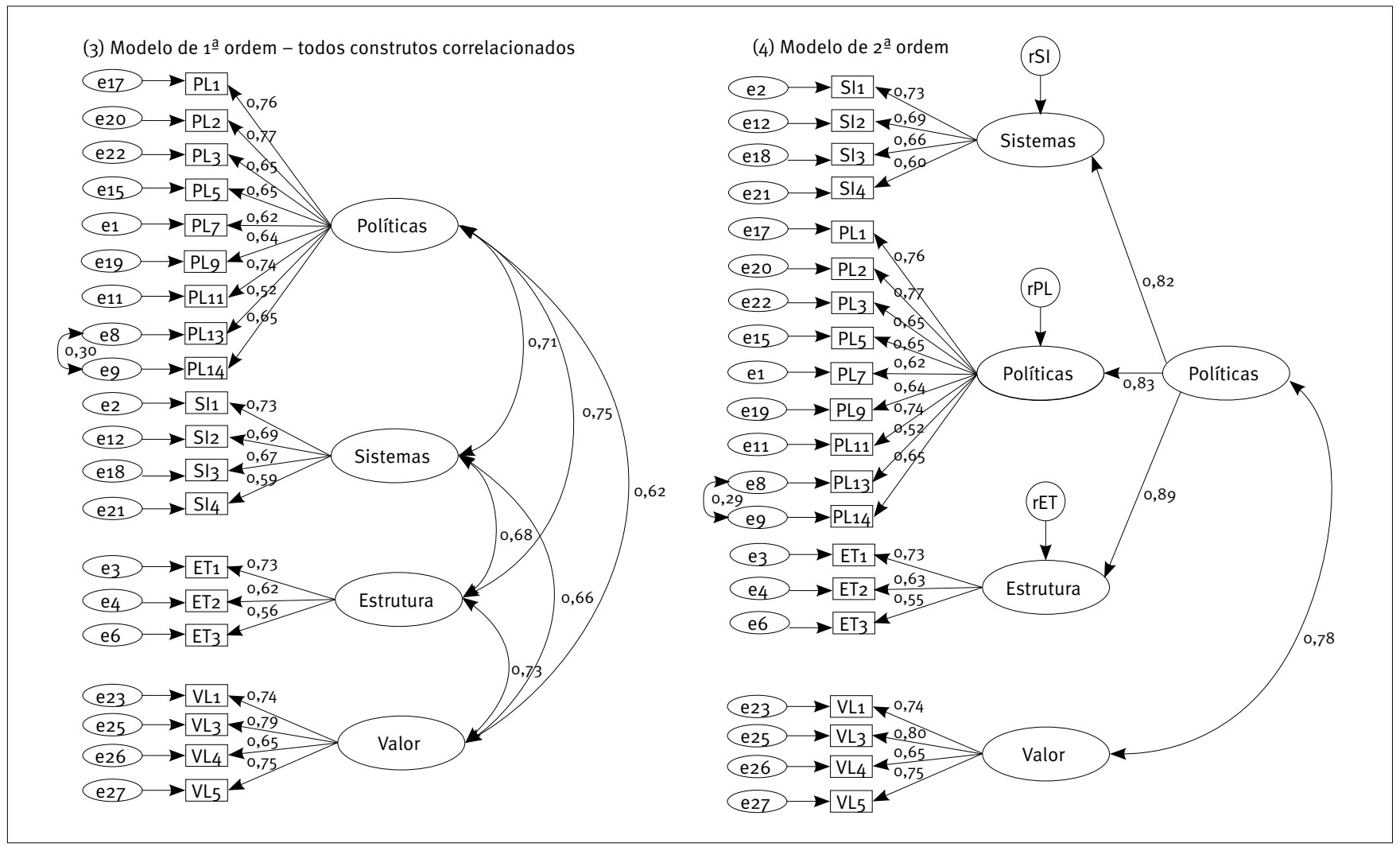

Fonte: AMOS

Nas duas figuras anteriores, é possível observar os quatro modelos alternativos, conforme proposto por Koufteros et al. (2009) nos passos 3 a 6 descritos anteriormente, que foram inseridos e testados no AMOS. Na Tabela 2, estão relacionados os índices de ajustamento obtidos para os quatro modelos analisados.

Tabela 2. Índices de ajustamento dos modelos de mensuração

\begin{tabular}{|c|c|c|c|c|c|}
\hline \multirow{2}{*}{ Índice } & \multirow{2}{*}{ Valor recomendado } & \multicolumn{4}{|c|}{ Modelo de Mensuração } \\
\hline & & 1 & 2 & 3 & 4 \\
\hline$X^{2} / d f$ & $\leq 3,00$ & 2.184 & 3.322 & 1.576 & 1.578 \\
\hline GFI & $\geq 0,90$ & 0,842 & 0,782 & 0,896 & 0,895 \\
\hline AGFI & $\cong 1,00$ & 0,802 & 0,729 & 0,866 & 0,866 \\
\hline TLI & $\cong 1,00$ & 0,872 & 0,749 & 0,938 & 0,937 \\
\hline IFI & $\cong 1,00$ & 0,888 & 0,779 & 0,947 & 0,946 \\
\hline PCFI & $\cong 1,00$ & 0,784 & 0,691 & 0,812 & 0,821 \\
\hline PNFI & $\cong 1,00$ & 0,717 & 0,633 & 0,745 & 0,752 \\
\hline$p$ & & 0,000 & 0,000 & 0,000 & 0,000 \\
\hline
\end{tabular}


Pelos números dos índices apresentados (estão destacados em negrito os melhores valores obtidos para cada índice), pode-se verificar que os modelos 1 e 2 são os que apresentam os piores resultados, bem inferiores aos obtidos pelos modelos 3 e 4 . 0 modelo 1 e seus índices muito pobres indicam as consequências adversas de se combinarem variáveis manifestas de vários domínios de conteúdo dentro de uma única variável latente de primeira ordem. 0 modelo 2 apresenta índices ainda piores que o modelo 1 , fato que já era esperado em virtude da alta correlação existente entre as variáveis latentes.

0 modelo 4, com construto de segunda ordem, tem índices muito próximos aos do modelo 3, que é o modelo de mensuração revisado apresentado anteriormente. Ambos têm fundamentação teórica consistente. Interessante observar, no modelo 4, as fortes cargas entre o construto de segunda ordem (a Gl) e os construtos de primeira ordem, políticas $(0,83)$, sistemas $(\mathrm{SI} / \mathrm{TI})(0,82)$ e estrutura $(0,89)$. Esse resultado é compatível com a teorização proposta no trabalho de que os três construtos representam os fatores da Gl.

No entanto, Koufteros et al. (2009) deixam claro que um modelo o qual inclui uma estrutura de segunda ordem nunca pode produzir um modelo ajustado (em termos dos índices de ajustamento do modelo) melhor que um modelo que especifica somente fatores correlacionados de primeira ordem. Apesar disso, em determinados casos, um modelo de segunda ordem que rivaliza em performance com um modelo correlacionado de primeira ordem pode ser uma alternativa atrativa.

De qualquer forma, o modelo de mensuração escolhido foi o de número 3, por apresentar os melhores índices. 0 modelo 3 apresenta números melhores ou iguais aos do modelo $4 \mathrm{em}$ todos os índices de ajustamento, à exceção dos índices de parcimônia PCFI e PNFI, que são ligeiramente inferiores.

\section{Modelo de regressão estrutural e as hipóteses}

A partir do modelo de mensuração revisado que foi apresentado na seção anterior, foi construído o modelo estrutural apresentado na Figura 5 com a utilização do software AMOS. Dois aspectos do modelo devem ser registrados. O primeiro é que o modelo é recursivo. Em modelos recursivos, todos os efeitos causais são unidirecionais, o que significa dizer que nenhuma das variáveis endógenas é especificada como causa e efeito uma da outra (Kline, 2012). O segundo aspecto é que o modelo é refletivo. Jarvis, Mackenzie e Podsakoff (2003) apresentam, em seu trabalho, uma análise sobre as regras que determinam se um construto é formativo ou refletivo. Nos modelos refletivos, os indicadores são especificados como endógenos, e os erros de mensuração são representados no nível do indicador (Kline, 2012).
O modelo estrutural proposto neste trabalho possui quatro construtos ou variáveis latentes, que são políticas, sistemas (SI/ TI), estrutura e valor. Esse conjunto de construtos é medido por 20 variáveis observadas, que são os ítens oriundos do instrumento de pesquisa aplicado na pesquisa survey com os executivos de TI dos bancos. Assim, o construto políticas é medido por nove itens, o construto sistemas (SI/TI), por quatro itens, o construto estrutura, por três itens, e o construto valor, por quatro itens.

As variáveis presentes no modelo são: a variável exógena (Políticas), que, no caso, também é a única variável independente, e as variáveis endógenas, que são representadas pelas duas variáveis mediadoras (sistemas (SI/TI) e estrutura) e pela variável dependente (valor). Na Figura 5, são indicadas as relações entre a variável exógena e as duas variáveis endógenas (mediadoras), e entre essas variáveis endógenas e a outra variável endógena. Também são registrados os erros das variáveis exógena e endógenas, e os resíduos das variáveis endógenas (rSI, rET, rVL).

$\mathrm{Na}$ Figura 5, pode-se verificar que o efeito direto entre os construtos políticas e valor é praticamente zerado pela mediação conjunta (ou múltipla) dos construtos sistemas ( $\mathrm{SI} / \mathrm{TI}$ ) e estrutura. As cargas dos construtos para os itens (variáveis observadas) variam de 0,52 a 0,79, e apenas três delas são inferiores a 0,60, estando duas dessas três na faixa de arredondamento desse número. A Tabela 3 lista as cargas fatoriais entre os construtos, os valores $t$ e seus respectivos níveis de significância.

$\mathrm{Na}$ presença da mediação múltipla, o efeito direto do construto políticas sobre o valor é zerado (chega a ficar ligeiramente negativo). Isso ocorre porque esse efeito passa a ser indireto, por intermédio das duas variáveis mediadoras, sistemas ( $\mathrm{SI} / \mathrm{TI})$ e estrutura.

Excluindo-se os valores do relacionamento políticas $\rightarrow$ valor, que se tornou não significativo com a mediação, os valores $t$ são superiores a $|2,576|$ (variaram de 3,028 a 8,319), as cargas fatoriais padronizadas entre os construtos são todas significativas com valores variando de 0,381 a o,775.

Os índices de ajustamento do modelo de regressão estrutural foram $\chi^{2} / d f=1,601$; RMSEA $=0,052 ; \mathrm{GFI}=0,892$; $\mathrm{AGFI}=0,862 ; \mathrm{CFI}=0,944 ; \mathrm{NFI}=0,865 ; \mathrm{TLI}=0,935 ; \mathrm{IFI}=0,945$; $\mathrm{PCFI}=0,815 ; \mathrm{PNFI}=0,747$. Todos esses índices atendem ou estão muito próximos dos valores de referência adotados neste estudo $\left(\chi^{2} / d f<3 ; \mathrm{RMSEA}<0,08 ; \mathrm{GFI}>0,90 ; \mathrm{AGFI} \cong 1,00 ; \mathrm{CFI}>0,90 ; \mathrm{NFI} \cong\right.$ 1,$00 ; \mathrm{TLI} \cong 1,00 ; \mathrm{IFI} \cong 1,00 ; \mathrm{PCFI} \cong 1,00 ; \mathrm{PNFI} \cong 1,00$ ), que foram obtidos a partir dos trabalhos de diversos autores (West, Taylor, \& Wu, 2012; Hooper, Coughlan, \& Mullen, 2008; SchermellehEngel, Moosbrugger, \& Müller, 2003). O GFI é o único índice que não atingiu o valor de referência, mas seu valor de o,892 é muito próximo de 0,90 e pode ser aceito (Hartono, Li, \& Simpson, 2010; Štemberger, Manfreda, \& Kovačič, 2011). 
Figura 5. Modelo de regressão estrutural com as cargas apuradas

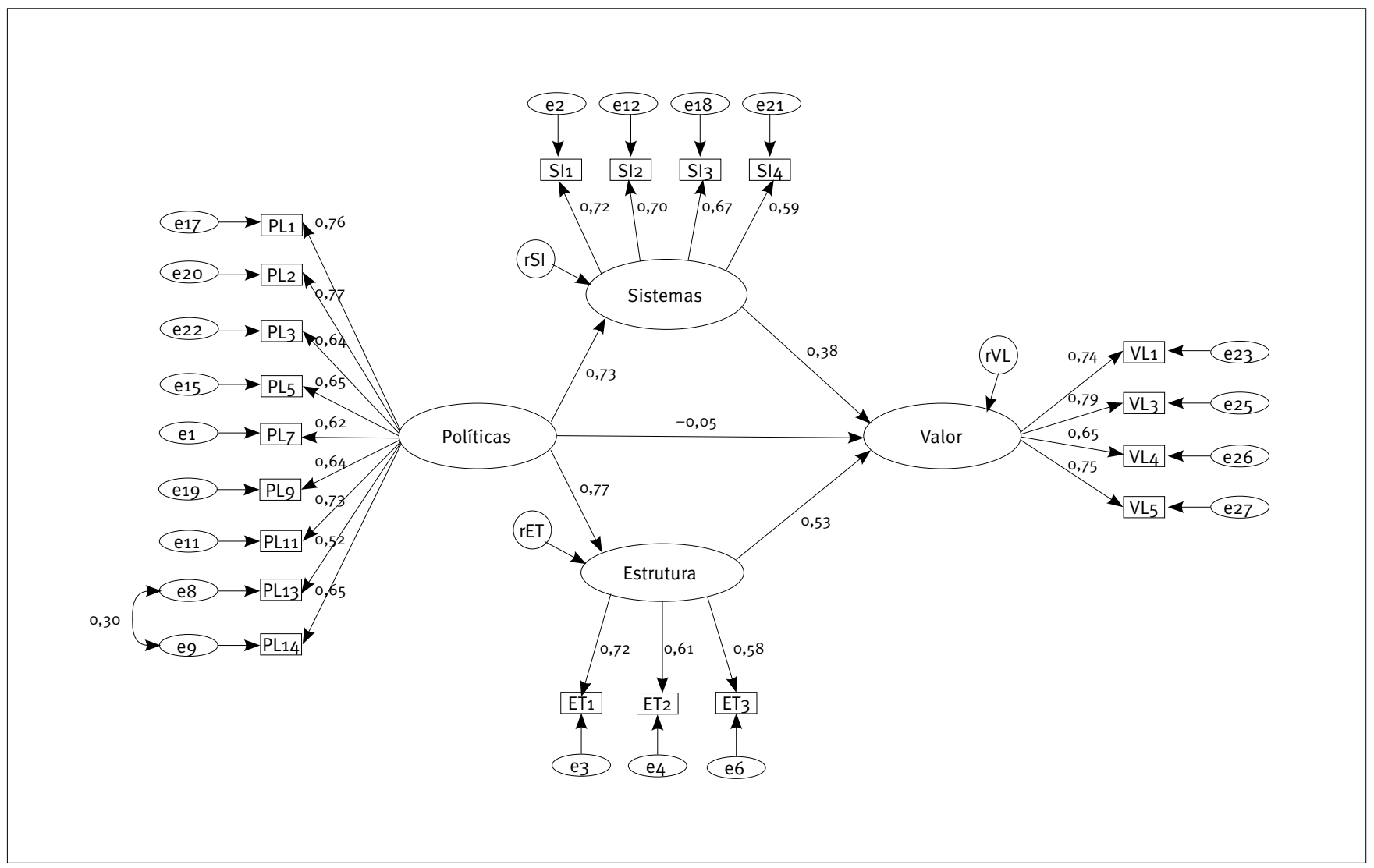

Fonte: AMOS

Tabela 3. Os relacionamentos entre os construtos no modelo de regressão estrutural

\begin{tabular}{|c|c|c|c|c|c|c|c|c|}
\hline \multicolumn{3}{|c|}{ Relacionamento Estrutural } & \multicolumn{6}{|c|}{ Pesos da regressão } \\
\hline Políticas & & Sistemas (SI/TI) & 0,836 & 0,103 & 8,109 & $\star \star \star ~$ & 0,726 & 0,699 \\
\hline Políticas & $-\rightarrow$ & Estrutura & 0,799 & 0,096 & 8,319 & $\star \star \star \star ~$ & 0,775 & 0,638 \\
\hline Estrutura & & Valor & 0,556 & 0,169 & 3,282 & 0,001 & 0,529 & 0,309 \\
\hline Sistemas (SI/TI) & $-->$ & Valor & 0,359 & 0,119 & 3,028 & 0,002 & 0,381 & 0,129 \\
\hline
\end{tabular}

$(* *) p<0,001$

Em relação às hipóteses propostas no trabalho, os resultados estatísticos apurados levaram à aceitação de todas elas. A hipótese $\mathrm{H}_{1}$ (O fator políticas está positivamente associado ao valor) foi suportada pelos dados analisados, com uma carga $\curlyvee=$ o,668 e significância $p<0,001$, quando analisada isoladamente sem a presença das relações de mediação no modelo. As políticas são as verdadeiras viabilizadoras das ações de $\mathrm{Gl}$ nos bancos.

A hipótese $\mathrm{H} 2$ (O fator políticas está positivamente associado ao fator sistemas ( $\mathrm{SI} / \mathrm{TI})$ ) foi suportada pelos dados, com uma carga $\gamma=0,745$ e significância $p<0,001$. A aceitação dessa relação indica que, na visão dos executivos de Tl que participaram da pesquisa, as políticas de GI têm influência sobre a área de $\mathrm{SI} / \mathrm{TI}$ dos bancos. 
A hipótese $\mathrm{H}_{3}$ (O fator políticas está positivamente associado ao fator estrutura) foi suportada pelos dados, com uma carga $\gamma=0,802$ e significância $p<0,001$. É a relação do fator políticas que apresenta maior carga, o que indica a importância da existência de uma estrutura formal de GI nos bancos.

A hipótese $\mathrm{H}_{4}$ (O fator sistemas ( $\mathrm{SI} / \mathrm{TI}$ ) está positivamente associado ao valor) foi suportada pelos dados analisados, com uma carga $\beta=0,411$ e significância $p<0,001$. A aceitação dessa hipótese indica a importância da área de TI para agregação de valor em um programa de GI.

Finalmente, a hipótese $\mathrm{H}_{5}$ (O fator estrutura está positivamente associado ao valor) foi suportada pelos dados, com uma carga $\beta=0,562$ e significância $p<0,001$. A existência da estrutura formal de GI viabiliza fortemente, na visão dos executivos de TI, a obtenção de valor.

\section{Contribuições da pesquisa}

Este trabalho visa contribuir com o preenchimento de algumas lacunas teóricas existentes nos estudos sobre GI. A primeira contribuição refere-se à proposição de um modelo de GI para os bancos. 0 modelo proposto conecta os fatores da GI (políticas, sistemas ( $\mathrm{SI} / \mathrm{TI})$ e Estrutura) ao fator valor nos bancos. Em outras palavras, com base na percepção dos executivos participantes da pesquisa, é possível agregar valor no negócio bancário investindo na GI.

Uma segunda contribuição é que o estudo propõe um direcionamento diferente para a GI. Ao enfatizar a importância das políticas de GI e da existência de uma estrutura formal de governança, o modelo reforça a necessidade de uma participação maior das áreas de negócio das empresas nas soluções relativas ao objeto "informação", sem a dominância quase sempre presente da área de tecnologia. Tallon, Ramirez, e Short (2013), por exemplo, apresentam, em seu estudo, um modelo com antecedentes, composição da GI e consequentes, mas com os antecedentes e a composição da GI fortemente baseados em práticas de TI.

Uma terceira contribuição refere-se à utilização de elementos das teorias organizacionais agência, visão baseada em recursos da firma (RBV) e capacidades dinâmicas na construção do modelo, ou seja, na identificação de seus itens e construtos. Da teoria da agência, destaca-se a visão de que a GI faz parte da governança corporativa e apoia o uso da informação pelos agentes no necessário accountability. Da RBV, pode-se destacar a utilização da informação como um recurso para obtenção de vantagem competitiva e geração de valor. Da teoria das capacidades dinâmicas, complementarmente à RBV, destaca-se o fato de os bancos desenvolverem suas capacidades de atingirem formas inovadoras de vantagem competitiva, dadas as condições de rápidas mudanças dos mercados em que atuam.

\section{CONSIDERAÇÕES FINAIS}

O estudo completo com os dados da survey, que foi realizada com a participação de 221 executivos de TI de bancos que atuam no Brasil, possibilitou o teste do modelo de regressão estrutural proposto no estudo.

Em relação às técnicas quantitativas, foi realizada análise multivariada, em especial a modelagem de equações estruturais (SEM), com a análise fatorial confirmatória e a análise de regressão estrutural (Blunch, 2008; Hoyle, 2012; Kline, 2011; Raykov \& Marcoulides, 2006). Toda a análise de validação do modelo foi feita seguindo-se a abordagem de Koufteros (1999) e Koufteros et al. (2009).

A análise quantitativa proporcionou como resultados a validação de um modelo de GI para os bancos e a análise dos efeitos dos fatores da GI sobre o valor na percepção dos executivos participantes. No modelo, os três fatores da GI são políticas, sistemas (SI/TI) e estrutura. O fator políticas representa o cerne do modelo de GI. 0 modelo propõe a adoção de políticas de accountability, acessibilidade, compartilhamento, compliance, comunicação, monitoramento e padronização, que tratariam não apenas dos aspectos relativos à geração ou recepção da informação, mas também do seu uso pela organização.

0 objetivo real da análise não é achar um modelo estrutural que se “encaixa” nos dados, mas, sim, testar a teorização proposta (Kline, 2011, p. 228). Assim, o que se buscou verificar com a utilização da modelagem de equações estruturais (SEM) foi saber se os três fatores indicados realmente compõem um construto maior, que se chamou de GI. Mais que isso, foi teorizado que existem efeitos diretos e indiretos entre esses construtos e o valor nos bancos. Dessa forma, os construtos sistemas (SI/TI) e estrutura medeiam a relação entre o fator políticas e o valor. As hipóteses propostas para a pesquisa, que envolviam as diversas relações diretas e indiretas entre os fatores do modelo de GI, foram todas comprovadas estatisticamente.

Conclui-se que o modelo estrutural proposto é consistente com os dados obtidos na survey, o que indicou que, para o grupo de executivos de TI participantes da pesquisa, as relações teóricas previstas no modelo refletem o que ocorre na realidade dos bancos. Portanto, de acordo com os executivos de TI participantes, os fatores políticas, sistemas (SI/TI) e estrutura podem ser considerados em um programa de $\mathrm{GI}$, e os fatores sistemas (SI/TI) e estrutura têm um importante papel no suporte e na habilitação, respectivamente, dessas políticas dentro dos bancos. 0 estudo 
indicou que as políticas de GI têm seus efeitos alcançados nos bancos por intermédio dos sistemas (SI/TI) e da sua estrutura formal de GI.

Em relação às limitações do estudo, podem ser citados a utilização de uma amostra de conveniência (do tipo "bola de neve"), que limita a generalização dos resultados; o corte transversal da pesquisa, devido ao qual as respostas dos executivos podem ter sido influenciadas por variáveis externas e momentâneas; e a avaliação dos construtos feita com base na percepção dos executivos de TI, e não em números objetivos.

Como sugestões para pesquisas futuras, são indicados a aplicação do instrumento da pesquisa no sistema bancário de outros países, de modo a complementar os resultados obtidos nesta pesquisa; o desenvolvimento de pesquisas em outros setores do sistema financeiro e em outras indústrias, de modo a verificar se as conclusões são semelhantes; e o desenvolvimento de novos instrumentos de pesquisa, com o intuito de medir o impacto das políticas e práticas de GI sobre o valor, por intermédio de variáveis numéricas dos resultados dos bancos.

\section{AGRADECIMENTOS}

O autor Fernando de Abreu Faria (Bolsista da Capes Proc. No. 0372/11-o) agradece o apoio da Coordenação de Aperfeiçoamento de Pessoal de Nível Superior (CAPES) e da Universidade Banco Central do Brasil (UniBC) para a realização da pesquisa.

0 autor Antonio Carlos Gastaud Maçada (Bolsa PQ 310995/2014) agradece o apoio do Conselho Nacional de Desenvolvimento Científico e Tecnológico (CNPq) e da Coordenação de Aperfeiçoamento de Pessoal de Nível Superior (CAPES).

\section{REFERÊNCIAS}

Bagozzi, R. P., \& Yi, Y. (2012). Specification, evaluation, and interpretation of structural equation models. Journal of the Academy of Marketing Science, 40(1), 8-34. doi:10.1007/s11747-011-0278-x

Banco Central do Brasil. (2013). 50 maiores bancos e o consolidado do sistema financeiro nacional. Recuperado de http://www4.bcb.gov. $\mathrm{br} /$ top5o/port/top50.asp

Beath, C., Becerra-Fernandez, I., Ross, J., \& Short, J. (2012, June). Finding value in the information explosion. MIT Sloan Management Review. Recuperado de http://sloanreview.mit.edu/
Beccalli, E. (2007). Does IT investment improve bank performance? Evidence from Europe. Journal of Banking \& Finance, 31(7), 22052230. doi:10.1016/j.jbankfin.2006.10.022

Blunch, N. J. (2008). Introduction to structural equation modelling using SPSS and AMOS. Thousand Oaks, EUA: Sage.

Booth, A., Papaioannou, D., \& Sutton, A. (2012). Systematic approaches to a successful literature review. London, Reino Unido: Sage Publications.

Brown, T. A., \& Moore, M. T. (2012). Confirmatory factor analysis. In R. H. Hoyle, Handbook of structural equation modeling (pp. 361-379). New York, EUA: Guilford.

Brynjolfsson, E., \& Hitt, L. (1996). Paradox lost? Firm-level evidence on the returns to information systems spending. Management Science, 42(4), 541-558. doi:10.1287/mnsc.42.4.541

Campo, S., Rubio, N., \& Yagüe, M. J. (2010). Information technology use and firm's perceived performance in supply chain management. Journal of Business-to-Business Marketing, 17(4), 336-364. doi:10.1080/10517120903574649

Claver-Cortés, E., Pertusa-Ortega, E. M., \& Molina-Azorín, J. F. (2012). Characteristics of organizational structure relating to hybrid competitive strategy: Implications for performance. Journal of Business Research, 65(7), 993-1002. doi:10.1016/j. jbusres.2011.04.012

Dess, G. G., \& Robinson, R. B. (1984). Measuring organizational performance in the absence of objective measures: The case of the privately-hel firm and conglomerate business unit. Strategic Management Journal, 5(3), 265-273. doi:10.1002/smj.4250050306

Donaldson, A., \& Walker, P. (2004). Information governance: A view from the NHS. International Journal of Medical Informatics, 73(3), 281-284. doi:10.1016/j.ijmedinf.2003.11.009

Falk, M. (2005). ICT-linked firm reorganization and productivity gains. Technovation, 25(11), 1229-1250. doi:10.1016/j. technovation.2004.07.004

Faria, F. A., \& Maçada, A. C. G. (2011). Impacto dos investimentos em TI no resultado operacional dos bancos brasileiros. RAE-Revista de Administração de Empresas, 51(5), 440-457. doi:10.1590/So03475902011000500003

Faria, F. A., Maçada, A. C. G., \& Kumar, K. (2013). Information governance in the banking industry. Proceedings of the $46^{\text {th }}$ Hawaii International Conference on System Sciences (HICSS), Hawaii, EUA.

Faria, F. A., \& Sympson, G. (2013). Bridging the gap between business and IT: An information governance perspective in the banking industry. In N. Bhansali, Data governance: Creating vaue from information assets (pp. 217-241). Boca Raton, USA: Taylor \& Francis.

Fornell, C., \& Larcker, D. F. (1981). Evaluating structural equation models with unobservable variables and measurement error. Journal of Marketing Research, 18(1), 39-50. doi:10.2307/3151312

Grembergen, W. Van, \& Haes, S. (2009). Enterprise governance of information technology. New York, EUA: Springer.

Hartono, E., Li, X., Na, K. S., \& Simpson, J. T. (2010). The role of the quality of shared information in interorganizational systems use. International Journal of Information Management, 30(5), 399-407. doi:10.1016/j.ijinfomgt.2010.02.007

Hill, D. G. (2008). Information governance is a necessity. ON Magazine, (3), 32-34. Recuperado de https://www.emc.com/collateral/ magazine/on-mag-3-2008-interactive.pdf 
Hooper, D., Coughlan, J., \& Mullen, M. R. (2008). Structural equation modelling: Guidelines for determining model fit. The Electronic Journal of Business Research Methods, 6(1), 53-60.

Hoyle, R. H. (2012). Introduction and overview. In Hoyle, R. H., Handbook of structural equation modeling (pp. 3-16). New York, EUA: Guilford.

International Data Corporation. (2014). The digital universe of opportunities: Rich data and the increasing value of the internet of things. Recuperado de http://brazil.emc.com/leadership/digitaluniverse/2014iview/executive-summary.htm

Jarvis, C. B., Mackenzie, S. B., \& Podsakoff, P. M. (2003). A critical review of construct indicators and measurement model misspecification in marketing and consumer research. Journal of Consumer Research, 30(2), 199-218. doi:10.1086/376806

Kline, R. B. (2011). Principles and practice of structural equation modeling (3rd ed.). New York, EUA: Guilford.

Kline, R. B. (2012). Assumptions in structural equation modeling. In R. H. Hoyle, Handbook of structural equation modeling (pp. 111-125). New York, EUA: Guilford.

Kooper, M. N., Maes, R., \& Lindgreen, R. (2011). On the governance of information: Introducing a new concept of governance to support the management of information. International Journal of Information Management, 31(3), 195-200. doi:10.1016/j.ijinfomgt.2010.05.009

Koufteros, X. (1999). Testing a model of pull production: A paradigm for manufacturing research using structural equation modeling. Journal of Operations Management, 17(4), 467-488. doi:10.1016/S02726963(99)00002-9

Koufteros, X., Babbar, S., \& Kaighobadi, M. (2009). A paradigm for examining second-order factor models employing structural equation modeling. International Journal of Production Economics, 120(2), 633-652. doi:10.1016/j.ijpe.2009.04.010

Lajara, T. T., \& Maçada, A. C. G. (2013, August). Information governance framework: The defense manufacturing case study. Proceedings of the Nineteenth Americas Conference on Information Systems (AMCIS), Chicago, EUA.

Lamberti, H. J., \& Büger, M. (2009). Lessons learned: 50 years of information technology in the banking industry - The example of Deutsche Bank AG. Business \& Information Systems Engineering, 1(1), 26-36. doi:10.1007/s12599-008-0033-0

Nakata, C., Zhu, Z., \& Kraimer, M. L. (2008). The complex contribution of information technology capability to business performance. Journal of Managerial Issues, $20(4)$, 485-506.

Pathan, S., \& Faff, R. (2012). Does board structure in banks really affect their performance? Journal of Banking \& Finance, 37(5), 1573-1589. doi:10.1016/j.jbankfin.2012.12.016

Prajogo, D., \& Olhager, J. (2012). Supply chain integration and performance: The effects of long-term relationships, information technology and sharing, and logistics integration. International Journal Production Economics, 135(1), 514-522. doi:10.1016/j. ijpe.2011.09.001
Qrunfleh, S., \& Tarafdar, M. (2012). Supply chain information systems strategy: Impacts on supply chain performance and firm performance. International Journal of Production Economics, 147 (Part B), 340-350. doi:10.1016/j.ijpe.2012.09.018

Raykov, T., \& Marcoulides, G. A. (2006). A first course in structural equation modeling (2nd ed.). New Jersey, EUA: Taylor \& Francis.

Samuelson, K. (2010). Information governance isn't so bad after all. 2010. Recuperado de http://www.cioupdate.com/insights/article. php/11049_3889396_2/Information-Governance-isnt-so-Bad-AfterAll.htm

Schermelleh-Engel, K., Moosbrugger, H., \& Müller, H. (2003). Evaluating the fit of structural equation models: Tests of significance and descriptive goodness-of-fit measures. Methods of Psychological Research Online, 8(2), 23-74.

Smallwood, R. F. (2011). Information governance fundamentals, best practices \& implementation issues. Recuperado de http://www.electronic-records-management.com/report_pages/Preview/Information-Governance-PRIMER2-March-2011-preview.pdf

Smallwood, R. F. (2014). Information governance: Concepts, strategies and best practices. New Jersey, EUA: John Wiley \& Sons.

Soares, S. (2011). Selling information governance to the business: Best practices by industry and job function. Ketchum, EUA: MC Press.

Štemberger, M. I., Manfreda, A., \& Kovačič, A. (2011). Achieving top management support with business knowledge and role of IT/IS personnel. International Journal of Information Management, 31(5), 428-436. doi:10.1016/j.ijinfomgt.2011.01.001

Tallon, P. P. (2007). Does IT pay to focus? An analysis of IT business value under single and multi-focused business strategies. Journal of Strategic Information Systems, 16(3), 278-300. doi:10.1016/j. jsis.2007.04.001

Tallon, P. P., Kraemer, K. L., \& Gurbaxani, V. (2000). Executives' perceptions of the business value of information technology: A process-oriented approach. Journal of Management Information Systems, 16(4), 145-173. doi:10.1080/07421222.2000.11518269

Tallon, P. P., Ramirez, R. V., \& Short, J. E. (2013). The information artifact in IT governance: Toward a theory of information governance. Journal of Management Information Systems, 30(3), 141-178. doi:10.2753/ mis0742-1222300306

The Economist. (2008). The future of enterprise information governance. The Economist Intelligence Unit. Recuperado de http://viewswire. eiu.com/report_dl.asp?mode=fi\&fi=1643883749.PDF

Weill, P., \& Ross, J. (2004). IT governance: How top performers manage IT decision rights for superior results. Boston, EUA: Harvard Business School Press.

West, S. G., Taylor, A. B., \& Wu, W. (2012). Model fit and model selection in structural equation modeling. In R. H. Hoyle, Handbook of structural equation modeling (pp. 209-231). New York, EUA: Guilford.

Weston R., \& Gore, P. A., Jr. (2006). A brief guide to structural equation modeling. The Counseling Psychologist, 34(5), 719-751. doi:10.1177/0011000006286345 